Article

\title{
Residents' Support Intentions and Behaviors Regarding Urban Trees Programs: A Structural Equation Modeling-Multi Group Analysis
}

\author{
Zheng Zhao ${ }^{1}$, Yaoqi Zhang ${ }^{2, *}$ and Yali Wen ${ }^{1}$ \\ 1 School of Economics and Management, Beijing Forestry University, Beijing 100083, China; \\ danios@163.com (Z.Z.); wenyali2003@163.com (Y.W.) \\ 2 School of Forestry and Wildlife Sciences, Auburn University, Auburn, AL 36849-5418, USA \\ * Correspondence: zhangy3@auburn.edu; Tel.: +1-334-844-1041
}

Received: 5 December 2017; Accepted: 25 January 2018; Published: 31 January 2018

\begin{abstract}
Urban trees are more about people than trees. Urban trees programs need public support and engagement, from the intentions to support to implement actions in supporting the programs. Built upon the theory of planned behavior and Structural Equation Modeling (SEM), this study uses Beijing as a case study to investigate how subjective norm (cognition of urban trees), attitude (benefits residents' believe urban trees can provide), and perceived behavioral control (the believed ability of what residents can do) affect intention and its transformation into implemented of supporting action. A total of 800 residents were interviewed in 2016 and asked about their opinion of neighborhood trees, park trees, and historical trees, and analyzed, respectively. The results show that subjective norm has a significant positive effect on intentions pertaining to historical and neighborhood trees. Attitudes influence intentions, but its overall influence is much lower than that of the subjective norm, indicating that residents are more likely to be influenced by external factors. The perceived behavioral control has the strongest effect among the three, suggesting the importance of public participation in strengthening intention. The transformation from intention to behavior seems relatively small, especially regarding neighborhood trees, suggesting that perceptions and participation need to be strengthened.
\end{abstract}

Keywords: residents' cognition; perception; structural equation modeling; historical trees; Beijing

\section{Introduction}

Fast growing urban population and increasing pollution have led to serious urban ecological and environmental problems. Urban trees, an important part of urban green infrastructure in providing ecosystem functions, are thus becoming increasingly important [1,2]. Previous research shows that urban trees can improve environmental quality [3,4], remove certain kinds of pollutants [5], change the appearance of the city [6], enhance public health and quality of life $[7,8]$, meet the needs of public leisure and recreation [9], and provide a habitat for urban wildlife [10]. Previous research also suggests that urban trees could promote urban and community development and provide for a wide range of goods and services to the society [11,12].

Social awareness of environmental protection and the value of urban trees are gradually deepening each other. Dwyer et al. [13] indicated that public feedback could help to improve the development of urban trees. People pay great attention to environmental quality of their city [14]. People's willingness to support urban trees is reflected in their cognition, preference and familiarity of urban trees, as well as feedback to the development of urban trees. The role of residents in urban trees can be manifested through their intentions to support urban trees, which are used as a criterion for measuring public preferences and needs of urban trees. Support intentions represent the amount of voluntary 
expenditure or other forms of support by individuals for the goods or services generated by urban trees. Understanding residents' awareness and intentions for supporting urban trees has become an important part of research on urban forests $[15,16]$.

Studies on residents' recognition and willingness to support urban trees have been conducted from different perspectives. Lorenzo et al. [17], taking small cities as an example, studied willingness to pay for urban trees. Saz-Salazar and Garcia-Menendez [18] discussed people's willingness to pay for urban trees for their role in overall urban environmental improvement in large cities. Zhang and Zheng [19,20] measured and analyzed people's supports of urban trees in southern American cities, and Zhu and Zhang [21,22] conducted a study about residents' demands for urban trees in large cities in the USA. Collectively, these studies suggest that people's individual characteristics such as age, occupation, education level and even nationality will have an impact on their perceptions and preferences of urban trees. Moreover, individuals are likely to have different views about urban trees in different times and places. A country's degree of openness, availability of information, and individuals' familiarity with urban trees will influence their cognition [23].

The purpose of this study was to further explore residents' perspectives on urban trees, using Beijing, China as an example. Specifically, we focused on residents' support intentions and action for different urban tree forms, which included neighborhood trees, park trees and protected historical trees in Beijing. We applied a structural equation modeling-based multi-group analysis to explore how intentions and actions varied toward these forms of urban trees, and focused on the overall mechanism of intentions and behaviors consistent with the theory of planned behavior. Structural equation modeling is widely used in psychology, management, sociology and other social science research, because it can account for the role of latent variables that is otherwise difficult to analyze and measure [24].

The study will contribute to earlier studies in which attitudes, perception, intention and implementation of action were not distinguished. Beijing is used a case study to investigate how the intention is affected by subjective norm, attitude, and perceived behavioral control, and the mechanism of into implemented of intention into action, and the factors of the transformation. Another contribution of this study is to explore the differences of attitudes, perception, supporting intentions and action regarding neighborhood trees, park trees and historical trees.

\section{Materials and Methods}

\subsection{Selection of Study Areas}

In China, urban trees have been promoted through urban development plans including "garden city", "eco-city" and other ecological advancement development strategies. China has built 13,662 urban parks and total urban green area has reached 188.8 million ha, which accounts for $36.34 \%$ of its urban areas [25]. However, development of urban trees in China has not kept paced with the rapid urban and regional development in the last 30 years. The lack of public participation and awareness could be part of the reason [26]. In fact, urban trees and greenings are public choices, heavily dependent on public participation and support of residents [13].

As the capital city of China, Beijing has many parks and gardens built based on old trees and royal gardens. Canopy cover rate of the city has reached $42.30 \%$, and the role of urban trees has become increasingly prominent [27]. It is argued that cities with a higher GDP per capita should have higher urban trees coverage, and more stringent standards and long-term goals are needed to meet the demands of Beijing's future development [28]. Beijing's population reached 21.73 in 2016, and urban trees development is, thus, needed to meet the ever growing population. Research has shown that development of urban trees and objectives will largely depend on the support of urban residents [29].

The study was designed keeping in consideration Beijing's expansion and greening patterns as sketched in Figure 1, and sample residents were randomly selected within the 5th Ring Road in Beijing. The selection of survey sites was based on stratified sampling of parks, universities, communities and firms, with full consideration of the location, size of urban areas and the number of residents. 


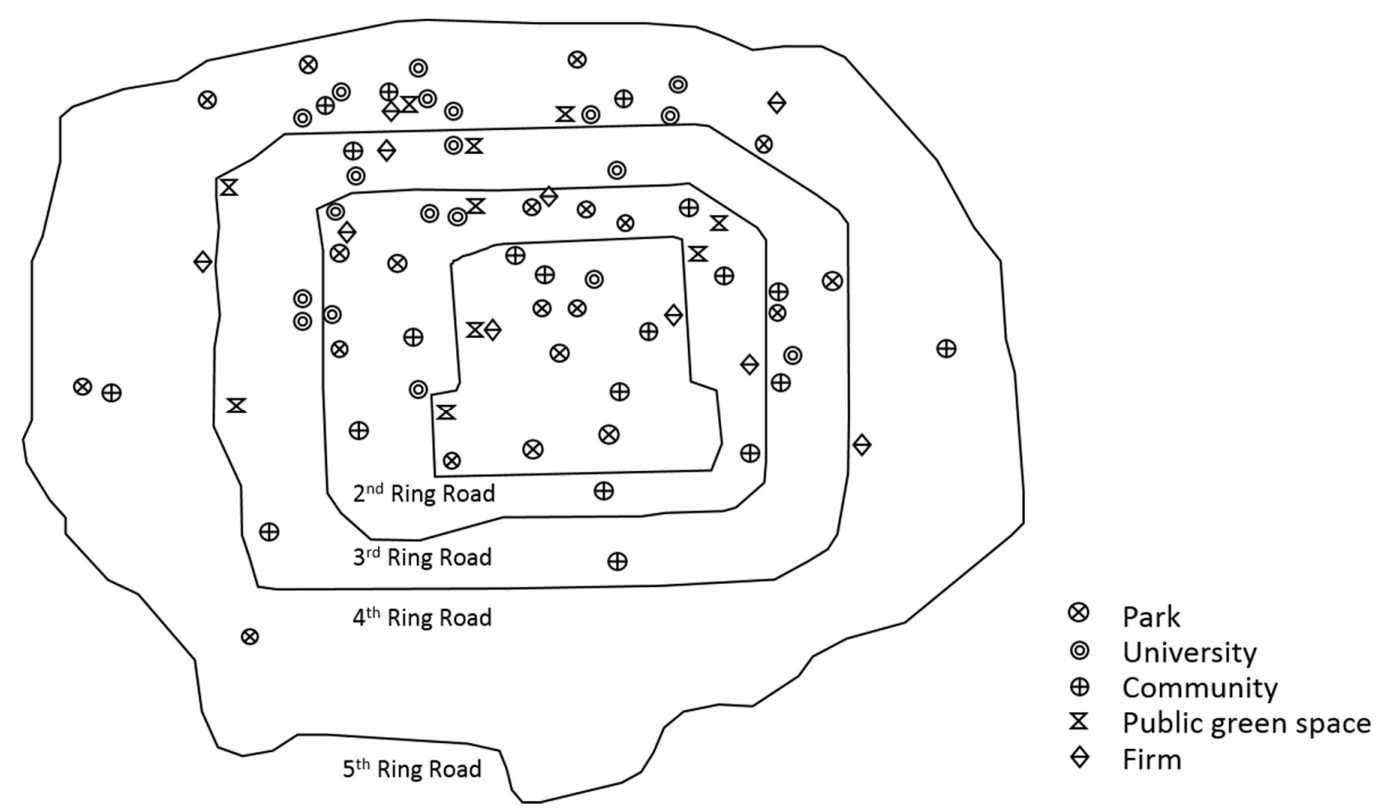

Figure 1. Survey sites, Beijing, China.

\subsection{Field Survey Design}

Field survey locations were distributed across 20 parks, 20 universities, 20 communities, 10 public green spaces and 10 firms. As Beijing's royal gardens and ancient parks are mostly dispersed across universities and parks, nearly half of the respondents were selected at universities and parks. These are more likely the locations where there is either a "liberal" attitude towards environmental issues, or individuals surveyed are actively involved in the green spaces. We conducted a three-day training program for all investigators, who were mostly undergraduate or graduate students, prior to the survey to help them get familiarized with the structure and content of the questionnaire. The survey involved face-to-face interviews, and investigators were responsible for answering respondents' questions during their interviewing processes. Face-to-face interviews were also conducted with some older respondents.

Beijing's existing urban tree forms are relatively diverse, but, based on their spatial distribution and density, most them can be classified as neighborhood trees, park trees and historical trees. Neighborhood trees refer to trees planted in the residential area, such as community green spaces; park trees refer to a variety of trees within the scope of the park, which usually belong to public areas rather than private residential areas; historical trees refer to protected ancient and famous trees.

In total, 2400 residents were interviewed regarding their support for urban trees in Beijing in 2016, with 800 residents each answering questions focused on neighborhood trees, park trees, and historical trees. The survey resulted in 2337 valid questionnaires for a response rate of $97 \%$. In terms of socio-demographic characteristics, females were slightly more than males; $63.74 \%$ of the respondents were 21 to 40 years old; $63.38 \%$ of the respondents had a bachelor degree or higher degree; $27.18 \%$ and $27.09 \%$ of the respondents were employees and retirees; and self-employed, civil servants and students were small in number. Respondents with personal annual income of 60-100 thousand yuan was close to $40 \%$; about $57.03 \%$ of the respondents lived in Beijing for 10 years or less, and only $9.54 \%$ of the respondents had lived in Beijing for more than 50 years; $80.08 \%$ of the respondents lived in Beijing for 10-12 months per year; and less than $4 \%$ stayed only on short-term basis.

\subsection{Model and Variables Setting}

This study is based on the theory of planned behavior (TPB). The theory believes that individuals' behavior could be affected by their intention, which is influenced by "subjective norm", "attitude" and 
"perceived behavioral control". Subjective norm refers to an individual's perceived social pressure to perform or not to perform a behavior, and attitude is the degree to which one individual has a favorable or unfavorable evaluation or appraisal of a behavior, while perceived behavioral control refers to the perceived difficulty of performing a behavior, and is assumed to reflect past experience as well as anticipated impediments and obstacles.

According to TPB, behavior could be affected by individuals' intention directly, and also influenced by their subjective norm, attitude and perceived behavioral control indirectly. Based on the TPB and related research findings, especially the specifications proposed by Bollen [30], three influencing factors were determined. In Structural Equations Modeling (SEM) terminology (Figure 2), these include three exogenous latent variables of Subjective Norm (A1), Attitude (A2) and Perceived Behavioral Control (A3), and two endogenous latent variables including Intention (B1) and Behavior (B2).

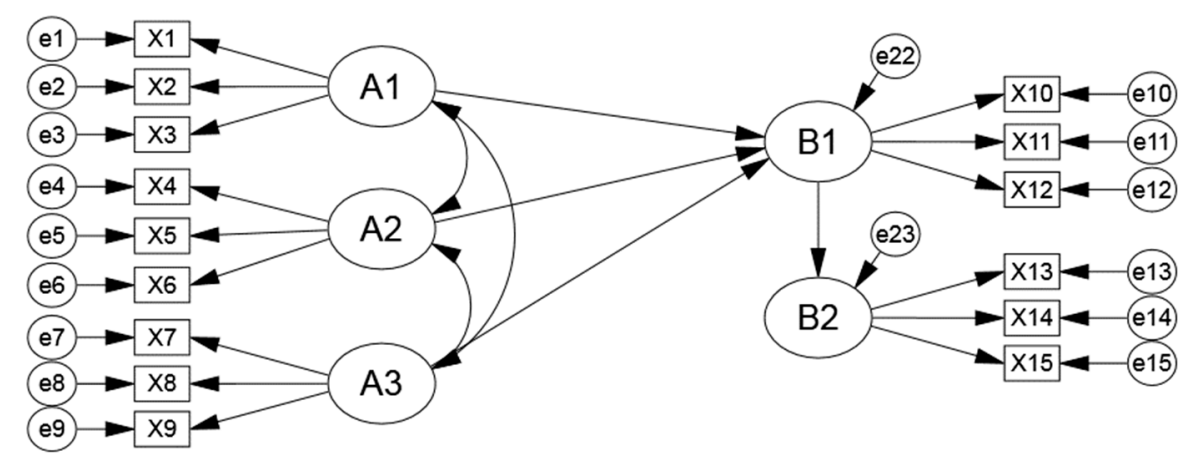

Figure 2. Model setting.

In SEM terminology, Subjective Norm (A1), Attitude (A2) and Perceived Behavioral Control (A3) are exogenous latent variables, whereas Intention (B1) and Behavior (B2) are endogenous latent variables. Each of the latent variables has three manifest variables (X1 to X15) and corresponding error terms (e1 to e15). The endogenous latent variables B1 and B2 also have corresponding error terms (e22 and e23).)

We used a Likert Scale with 5 response levels ( 1 as the smallest, 5 being the biggest) in assigning latent variables to their corresponding manifest variables. In Table 1, we present the two sets of variables.

Additional details regarding the latent variables and corresponding manifest variables are given below.

Subjective Norm (A1): The stronger the respondents' subjective norm, the stronger their intention would be. Residents' urban trees support intention could be affected by subjective norm, namely the external factors affecting their decisions [20]. Urban trees support intention is affected by subjective norm, which can be affected by government policies (X1), family relatives' opinions (X2), as well as friends and neighbors' opinions (X3) simultaneously.

Attitude (A2): People usually possess many "behavioral beliefs" about the possible behavioral outcomes; positive beliefs and cognitions would result in a strong willingness to behave and thus influence their decision-making. Accordingly, expected results and assessment of residents' support for urban trees could have an impact on their intention. Residents' "attitude" in this study refers to their estimation of the potential benefits from supporting urban trees, including social benefits (X4), economic benefits (X5) and eco-environmental benefits (X6), and transfer to support intentions. 
Table 1. Variables setting.

\begin{tabular}{|c|c|c|c|}
\hline \multicolumn{2}{|r|}{ Latent Variables } & \multicolumn{2}{|r|}{ Manifest Variables } \\
\hline A1 & Subjective Norm & $\begin{array}{l}\mathrm{X} 1 \\
\mathrm{X} 2 \\
\mathrm{X} 3\end{array}$ & $\begin{array}{c}\text { Your cognition of urban trees can be influenced by . } \\
\text { government policies } \\
\text { family relatives' opinions } \\
\text { friends' opinions }\end{array}$ \\
\hline A2 & Attitude & $\begin{array}{l}\text { X4 } \\
\text { X5 } \\
\text { X6 }\end{array}$ & $\begin{array}{l}\text { You believe that urban trees can bring you ... } \\
\text { social benefits } \\
\text { economic benefits } \\
\text { eco-environmental benefits }\end{array}$ \\
\hline A3 & Perceived Behavioral Control & $\begin{array}{l}\text { X7 } \\
\text { X8 } \\
\text { X9 }\end{array}$ & $\begin{array}{l}\text { You believe you have the ability to... } \\
\text { give financial support to urban trees program } \\
\text { participate in related activities of urban trees } \\
\text { supervise the development of urban trees }\end{array}$ \\
\hline B1 & Intention & $\begin{array}{l}\mathrm{X} 10 \\
\mathrm{X} 11 \\
\mathrm{X} 12 \\
\end{array}$ & $\begin{array}{l}\text { You have the intentions... } \\
\text { to support the legislation of urban trees } \\
\text { to support the good management of urban trees } \\
\text { to support the propaganda of urban trees }\end{array}$ \\
\hline B2 & Behavior & $\begin{array}{l}\text { X13 } \\
\text { X14 } \\
\text { X15 }\end{array}$ & $\begin{array}{c}\text { You once have.... } \\
\text { supported the legislation of urban trees } \\
\text { supported the good management of urban trees } \\
\text { supported the propaganda of urban trees }\end{array}$ \\
\hline
\end{tabular}

Perceived Behavioral Control (A3): People's behavior is not only affected by their subjective norms and attitudes, but also by their perceptions of their ability. Perceived behavioral control refers to residents' perceptions of their ability to overcome potential difficulties to implement their action when making their decisions. If people feel it relatively easy for them to support urban trees, then they tend to have higher perceived behavioral control, vice versa. In this case, perceived behavioral control includes residents' abilities to give financial support to urban trees program (X7), to participate in related activities of urban trees (X8), and to supervise the development of urban trees (X9). This suggests that, if people believe their abilities are stronger, then they will have higher perceived behavioral control. In effect, the higher the perceived behavioral control, the stronger the support intention of urban trees will be.

Intention (B1): Intention refers to residents' subjective willingness to support urban trees. Therefore, the Likert scale fully considered characteristics of urban trees in Beijing, as well as characteristics of survey samples, which includes their intentions to support legislation, good management and propaganda of urban trees (X10-X12, respectively). Propaganda about urban trees means a series of popular science, education and propaganda activities meant to promote participation of residents in the process of urban forestry development. Generally speaking, the more favorable the attitude and subjective norm of individuals' behavior, the greater the perceived behavioral control, and the stronger their intention to perform a certain behavior will be.

Behavior (B2): Behavior refers to residents' actual expenditure or other forms of support on urban trees. Since intention is a psychological state which cannot be directly observed, what really matters is their actual behavior, which we use to measure their support for legislation, good management and promotion, and public relation work of urban trees (X13-X15, respectively). It is believed that intentions would transfer into actions.

\section{Results}

Descriptive statistics of the variables used in this study are reported in Table 2. The results suggest that respondents' cognition of neighborhood trees and park trees is influenced mostly by government policies, and that of historical trees is mostly influenced by friends' opinions. Respondents believe that historical trees mainly generate social benefits. In contrast, trees induce economic, ecological and environmental benefits. However, the benefits associated with neighborhood trees are relatively small. Respondents generally believe they can support historical trees, which is reflective of the characteristics 
of urban forest in Beijing, as well as the importance of historical trees. The findings also indicate that respondents are more likely to support legislation and good management of historical trees, and promotion of park trees.

Table 2. Statistical results.

\begin{tabular}{ccccc}
\hline \multirow{2}{*}{ Latent Variables } & \multirow{2}{*}{ Manifest Variables } & \multicolumn{3}{c}{ Means } \\
\cline { 3 - 5 } & & Neighborhood Trees & Park Trees & Historical Trees \\
\hline \multirow{3}{*}{ A1 } & X1 & 3.568 & 3.720 & 3.544 \\
& X2 & 3.520 & 3.580 & 3.504 \\
& X3 & 3.676 & 3.708 & 3.688 \\
\hline \multirow{2}{*}{ A2 } & X4 & 3.248 & 3.224 & 3.268 \\
& X5 & 3.008 & 3.232 & 3.228 \\
& X6 & 3.224 & 3.384 & 3.212 \\
\hline \multirow{3}{*}{ A3 } & X7 & 2.764 & 2.816 & 2.816 \\
& X8 & 2.916 & 3.024 & 2.984 \\
& X9 & 3.048 & 3.208 & 3.076 \\
\hline \multirow{2}{*}{ B1 } & X10 & 2.940 & 2.920 & 2.924 \\
& X11 & 2.812 & 2.920 & 2.792 \\
& X12 & 3.100 & 3.236 & 3.156 \\
\hline \multirow{2}{*}{ B2 } & X13 & 2.248 & 2.280 & 2.480 \\
& X14 & 2.484 & 2.544 & 2.480 \\
& X15 & 2.404 & 2.500 & 2.652 \\
\hline
\end{tabular}

Before conducting structural equation modeling, reliability and validity tests were conducted, and the associated results are presented in Table 3. The respective Cronbach's $\alpha$ values of the sample data for neighborhood, park and historical trees are $0.830,0.823$ and 0.818 , which are higher than 0.7 (the standard value of the reliability test). This indicates that the sample data are reliable. KMO test values are, respectively, 0.768, 0.758 and 0.777; the approximate chi-squared values of Bartlett's spherical test were significant at the $1 \%$ level, indicating that the validity of the sample is ideal.

Table 3. Test results of reliability and validity ${ }^{1}$.

\begin{tabular}{|c|c|c|c|c|c|c|c|c|}
\hline \multirow{2}{*}{ Category } & \multicolumn{6}{|c|}{ Cronbach's $\alpha$ Test } & \multirow{2}{*}{ KMO Test } & \multirow{2}{*}{$\begin{array}{c}\text { Bartlett Test } \\
\text { (Chi-Square Sig.) }\end{array}$} \\
\hline & A1 & A2 & A3 & B1 & B2 & Total & & \\
\hline Neighborhood trees & 0.889 & 0.907 & 0.783 & 0.773 & 0.750 & 0.830 & 0.768 & $* * *$ \\
\hline Park trees & 0.921 & 0.904 & 0.775 & 0.775 & 0.764 & 0.823 & 0.758 & $* * *$ \\
\hline Historical trees & 0.892 & 0.903 & 0.781 & 0.780 & 0.711 & 0.818 & 0.777 & $* * *$ \\
\hline
\end{tabular}

Statistical estimation results of the models are presented in Figure 3a-c. For subjective norm, it is clear that government policies have the strongest effect, lending credence to the hypothesis that residents' support of urban trees strongly responds to policy, and the stability and sustainability of policy can enhance their confidence and willingness to support urban trees. However, friends' opinions have a relatively small effect on their subjective norms in neighborhood and historical trees than in park trees.

For attitude, city parks usually have large public green areas, and more likely bring economic benefits through related recreational facilities and tickets sale, while neighborhood trees are relatively close to people's daily lives and usually free of charge. People normally pay more attention to their social benefits. However, historical trees are more significant for their existence value and symbolic meaning; therefore, people do not have as many expectations of their social and economic effects.

For perceived behavioral control, people are more likely to give financial support to urban trees, and donations seem to be the most convenient, effective and feasible way for people to support urban trees. Currently, residents do not quite understand how to supervise the development of urban trees, 
and related activities are not very common in Beijing. Thus, people may believe their abilities are relatively weak.

Residents' support behaviors for legislation related to urban trees are much lower than the corresponding intentions. The results suggest people feel it is hard to participate in the legislative process in Beijing. Similarly, their actions to support good management and propaganda of urban trees are lower than their intentions. Since development and management of urban trees in Beijing are usually dominated by the government, public participation is thus limited.

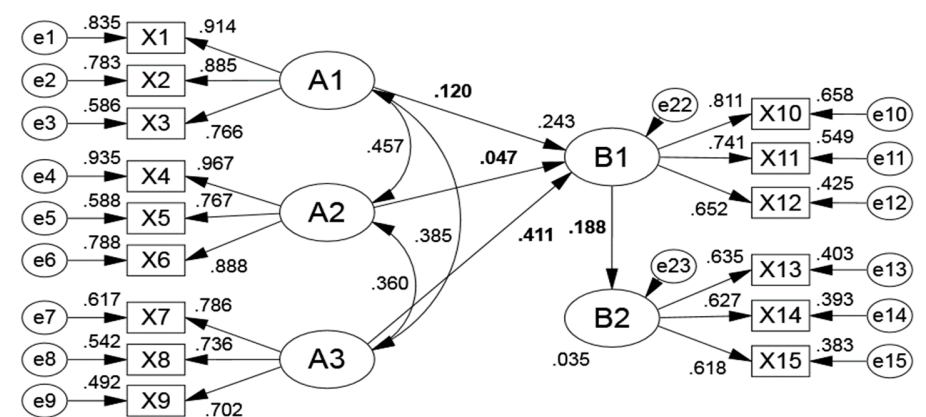

(a)

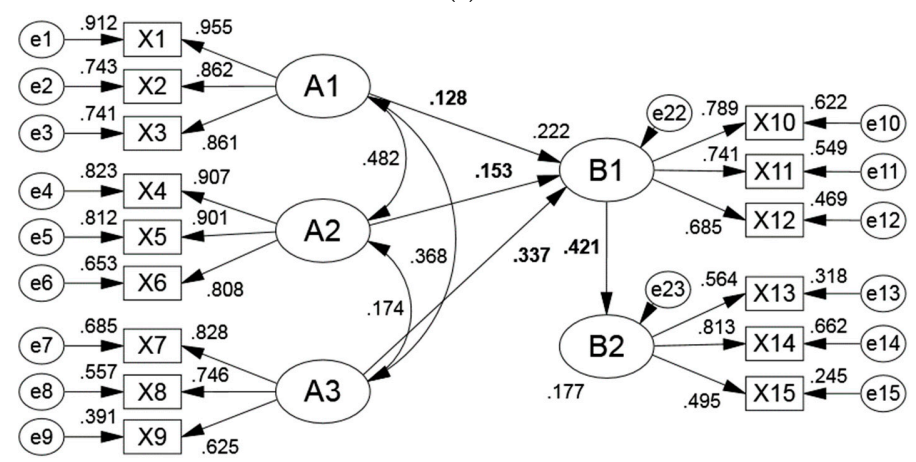

(b)

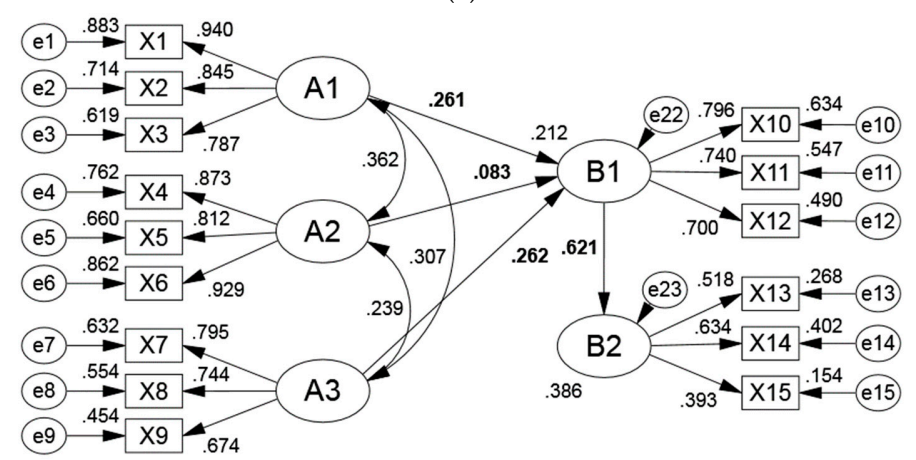

(c)

Figure 3. Standardized fitting results. (a) Standardized fitting results of neighborhood trees; (b) Standardized fitting results of park trees; (c) Standardized fitting results of historical trees.

In Figure 3a-c, numbers next to the arrow represent standardized fitting results of neighborhood, park and historical trees, which indicate the effect among the latent variables, the effect between the latent variable and the manifest variables, and the effect of the residual terms on the observation variables.

The standardized direct effects, standardized indirect effects, and standardized total effects are shown in Table 4. Direct effect represents the path coefficient of the structural model; the indirect effect represents the product of the associated direct effect; and the total effect is the sum of the direct and indirect effects. The overall results show that Subjective Norm, Attitude and Perceived Behavioral 
Control have direct effects on Intention and indirect effects on Behavior, while Intention only has direct effects on Behavior.

Table 4. The standardized multiple effects among the latent variables.

\begin{tabular}{|c|c|c|c|c|c|c|c|}
\hline \multirow{2}{*}{ Category } & & \multicolumn{3}{|c|}{ Effects on B1 } & \multicolumn{3}{|c|}{ Effects on B2 } \\
\hline & & Direct & Indirect & Total & Direct & Indirect & Total \\
\hline \multirow{4}{*}{ Neighborhood trees } & $\mathrm{A} 1$ & 0.120 & - & 0.120 & - & 0.023 & 0.023 \\
\hline & $\mathrm{A} 2$ & 0.047 & - & 0.047 & - & 0.009 & 0.009 \\
\hline & A3 & $0.411^{* * *}$ & - & 0.411 & - & 0.077 & 0.077 \\
\hline & B1 & - & - & - & $0.188^{* *}$ & - & 0.188 \\
\hline \multirow{4}{*}{ Park trees } & A1 & 0.128 & - & 0.128 & - & 0.054 & 0.054 \\
\hline & $\mathrm{A} 2$ & $0.153 *$ & - & 0.153 & - & 0.064 & 0.064 \\
\hline & A3 & $0.337^{* * *}$ & - & 0.337 & - & 0.142 & 0.142 \\
\hline & B1 & - & - & - & $0.421^{* * *}$ & - & 0.421 \\
\hline \multirow{4}{*}{ Historical trees } & A1 & $0.261^{* * *}$ & - & 0.261 & - & 0.162 & 0.162 \\
\hline & A2 & 0.083 & - & 0.083 & - & 0.051 & 0.051 \\
\hline & A3 & $0.262 * * *$ & - & 0.262 & - & 0.163 & 0.163 \\
\hline & B1 & - & - & - & $0.621^{* * *}$ & - & 0.621 \\
\hline
\end{tabular}

Based on the results presented in Figure $3 a-c$ and Table 4, we analyzed interactions between the five latent variables: (1) subjective norm has a significant positive effect on their support intentions of historical trees and neighborhood trees; (2) the overall influence of attitudes on intentions is much lower than that of subjective norm, indicating that residents are more likely to be influenced by external factors for payment decisions, and in which attitudes toward park trees have the greatest impact on intentions; (3) perceived behavioral control has the strongest effect among the three latent variables, and helps significantly increase the intention; and (4) consistent with theoretical assumptions underlying PBT, residents' support intentions indeed have significant positive direct impacts on their actions (Table 4), and the impact of intentions on actions also shows differently for urban tree areas: intentions play a greater role in historical as well as park trees than in neighborhood trees. Historical and park trees are more conspicuous urban tree types, and public awareness of their protection is relatively strong. A large gap exists between residents' support intentions and their actual actions, suggesting a weak transformation from subjective wills to real actions.

The three exogenous latent variables also have indirect effects on actions, and the overall effect of perceived behavioral control is higher than the other two: subjective norm and perceived behavioral control of historical trees have the biggest indirect effect on actions, while attitude of park trees have the biggest indirect effect on actions, suggesting the role of perceived behavioral control.

We also carried out model fitting quality test and report its results in Table 5. The overall fit of the structural equation model is fairly good. There is a high degree of agreement between the whole model and the sample data, which suggests that the external quality of the fitting outcome is good. The combined reliability values of the latent variables also indicate that the internal quality of the fitting outcome is good. 
Table 5. Results of fitting quality of structural equation modeling ${ }^{1}$.

\begin{tabular}{|c|c|c|c|c|c|c|}
\hline \multicolumn{3}{|c|}{ Types of Fitting Indexes } & \multicolumn{3}{|c|}{ Fitting Quality Results } & \multirow{2}{*}{$\begin{array}{c}\text { Optimal Evaluation } \\
\text { Criteria }\end{array}$} \\
\hline & & & Neighborhood Trees & Park Trees & Historical Trees & \\
\hline \multirow{9}{*}{ External quality } & \multirow{2}{*}{$\begin{array}{l}\text { Absolute fit } \\
\text { index }\end{array}$} & CMIN/DF & 2.805 & 2.656 & 1.896 & \multirow{2}{*}{$\begin{array}{l}\text { between } 1 \text { to } 3 \\
\text { smaller than } 0.05\end{array}$} \\
\hline & & RMSEA & 0.085 & 0.082 & 0.060 & \\
\hline & \multirow{5}{*}{$\begin{array}{l}\text { Relative fit } \\
\text { index }\end{array}$} & NFI & 0.876 & 0.888 & 0.909 & \multirow{5}{*}{$\begin{array}{l}\text { above } 0.9 \text {, the closer } \\
\text { to } 1 \text {, the better the fit }\end{array}$} \\
\hline & & RFI & 0.843 & 0.858 & 0.884 & \\
\hline & & IFI & 0.917 & 0.927 & 0.955 & \\
\hline & & TLI & 0.893 & 0.907 & 0.942 & \\
\hline & & CFI & 0.916 & 0.926 & 0.954 & \\
\hline & \multirow{2}{*}{$\begin{array}{c}\text { Parsimonious } \\
\text { fit index }\end{array}$} & AIC & 306.800 & 294.408 & 231.332 & \multirow{2}{*}{$\begin{array}{l}\text { the smaller the value, } \\
\text { the better the fit }{ }^{1}\end{array}$} \\
\hline & & CAIC & 474.094 & 461.703 & 398.626 & \\
\hline \multirow{5}{*}{ Internal quality } & \multirow{5}{*}{$\begin{array}{l}\text { Combined } \\
\text { reliability }\end{array}$} & A1 & 0.892 & 0.922 & 0.894 & \multirow{5}{*}{ above 0.6} \\
\hline & & $\mathrm{A} 2$ & 0.909 & 0.906 & 0.905 & \\
\hline & & $\mathrm{A} 3$ & 0.786 & 0.780 & 0.783 & \\
\hline & & B1 & 0.775 & 0.744 & 0.731 & \\
\hline & & $\mathrm{B} 2$ & 0.667 & 0.710 & 0.604 & \\
\hline
\end{tabular}

${ }^{1}$ In this study, the AIC value is smaller than the independence model value; the CAIC value is smaller than saturated model value and independence model, which indicates that the parsimonious fit index is relatively small.

\section{Discussion and Conclusions}

This study investigated the public's intention and action regarding three typical urban tree types (neighborhood trees, park trees, and historical trees) in Beijing, China. Structural equation modeling was used to better cope with an array of statistical issues, understand the overall mechanism of residents' support intentions and actions through a multi-group analysis, as well as factors affecting the intentions. The study offers useful insights and fills gaps in related research areas.

The findings of the study accord with the Theory of Planned Behavior (TPB), and are in line with previous research [15]. We found that perceived behavioral control shows the biggest effect on both intentions and actions. While neighborhood trees are the focus of attention, residents have stronger practical support for historical trees. A possible explanation might be the aesthetic and historical significance of historical trees in attracting people's support. While the role of the neighborhood tree and the park tree is great, their importance is not as appreciated as it should be.

These findings have important policy implications. First, active social engagement can play an important role in enhancing individual's urban tree support intention, as other people's opinions would affect their subjective norms. Second, given that residents' unclear attitude toward urban trees could result in a low level of intention, the Beijing city administration needs to involve the public in the development of urban trees programs and imparting knowledge about the importance of their understanding of urban trees in providing multiple functions. Third, it is important to formulate and implement urban tree policies to meet the residents' needs. While residents' participation is very important in the whole development process of urban trees, current public support channels of urban trees are still very limited. For example, the criterion for donations is inadequate in Beijing. Ji et al. (2017) has pointed out that a barrier to the green urban development in China is the absence of a clear vision and target [31]. Fourth, as neighborhood trees and park trees occupy a larger area of urban regions than historical trees, they need to be targeted and promoted. Consistent with previous research on transforming peoples' good wishes into practical actions [32], this study shows that the current level of transformations is relatively low. Specifically, the intentions of historical trees have a bigger influence on actions, which indicates that historical trees are considered more important and valuable than other urban tree forms. This is consistent with the nature of importance of Beijing's historical trees for their existence and conservation value. We believe that, as people realize the importance of other urban trees forms, the transformation from their intentions to actions of all kinds of urban trees will be accelerated. To achieve this goal, all urban tree forms need to get more publicity for their importance, not only the historical trees alone.

While the structural equation model can be used as an effective method in understanding the underlying mechanism of residents' support intentions and actions of urban trees, a more comprehensive approach is needed to investigate urban tree development. In particular, future 
studies should proceed from a comparison of intentions and actions between different types of cities and different seasons. Further investigation of people's psychological mechanism should be integrated into the study. Since urban trees are more about people than trees, and the urban forests are perceived is important, awareness education and public media are important for promoting the development of urban trees program.

Acknowledgments: This study is financially supported by Beijing Municipal Bureau of Arboriculture and Greening and Chinese Scholarship Council. We also thank for Anwar Hussain and Elina Zhang for their language editing.

Author Contributions: Zheng Zhao and Yaoqi Zhang conceived and designed the experiments; Zheng Zhao and Yali Wen performed the experiments; Zheng Zhao analyzed the data; Zheng Zhao contributed reagents/materials/analysis tools; and Zheng Zhao wrote the paper.

Conflicts of Interest: The authors declare no conflict of interest. The founding sponsors had no role in the design of the study; in the collection, analyses, or interpretation of data; in the writing of the manuscript, and in the decision to publish the results.

\section{References}

1. Qiu, E.F.; Wang, C.; Jia, B.Q.; Fan, B.M.; Xu, C.Y.; Zhang, Z.Q. Development Trend on Urban Forestry in China and Overseas. World For. Res. 2007, 20, 40-44.

2. Conedera, M.; Del Biaggio, A.; Seeland, K.; Moretti, M.; Home, R. Residents' preferences and use of urban and peri-urban green spaces in a Swiss mountainous region of the Southern Alps. Urban For. Urban Green. 2015, 14, 139-147. [CrossRef]

3. Irga, P.J.; Burchett, M.D.; Torpy, F.R. Does urban forestry have a quantitative effect on ambient air quality in an urban environment? Atmos. Environ. 2015, 120, 173-181. [CrossRef]

4. Xue, F.; Li, X. The impact of roadside trees on traffic released PM 10 in urban street canyon: Aerodynamic and deposition effects. Sustain. Cities Soc. 2017, 30, 195-204. [CrossRef]

5. Jim, C.Y.; Chen, W.Y. Ecosystem services and valuation of urban forests in China. Cities 2009, 26, 187-194. [CrossRef]

6. Fetene, A.; Worku, H. Planning for the conservation and sustainable use of urban forestry in Addis Ababa, Ethiopia. Urban For. Urban Green. 2013, 12, 367-379. [CrossRef]

7. Præstholm, S.; Jensen, F.S.; Hasler, B.; Damgaard, C.; Erichsen, E. Forests improve qualities and values of local areas in Denmark. Urban For. Urban Green. 2002, 1, 97-106. [CrossRef]

8. Clark, K.H.; Nicholas, K.A. Introducing urban food forestry: A multifunctional approach to increase food security and provide ecosystem services. Landsc. Ecol. 2013, 28, 1649-1669. [CrossRef]

9. Majumdar, S.; Deng, J.; Zhang, Y.; Pierskalla, C. Using contingent valuation to estimate the willingness of tourists to pay for urban forests: A study in Savannah, Georgia. Urban For. Urban Green. 2011, 10, 275-280. [CrossRef]

10. Monroe, M.C.; Jones, J.J.; Soldinger, A. Technical Note: Wildland-Urban Interface Forestry Success in Texas. South. J. Appl. For. 2012, 36, 107-109. [CrossRef]

11. Dwyer, J.F.; Schroeder, H.W.; Gobster, P. The significance of urban trees and forests: Toward a deeper understanding of values. J. Arboric. 1991, 17, 276-284.

12. Lohr, V.I.; Pearson-Mims, C.H.; Tarnai, J.; Dillman, D.A. How urban residents rate and rank the benefits and problems associated with trees in cities. J. Arboric. 2004, 30, 28-35.

13. Dwyer, J.F.; Nowak, D.J.; Watson, G.W. Future directions for urban forestry research in the United States. J. Arboric. 2002, 28, 231-236.

14. La Marca, O.; Bovio, G.; Bovo, G.; Sanesi, G. Aspetti metodologici nel piano di gestione del Parco della Maddalena-Arboretum Taurinense (Methodological aspects of the management plan of Maddalena's Park-Arboretum Taurinense). Annali. Accad. Ital. Sci. For. 1996, 45, 189-211.

15. Scarborough, V.L. How to interpret an ancient landscape. Proc. Natl. Acad. Sci. USA 2003, 100, 4366-4368. [CrossRef] [PubMed]

16. Gorman, J. Residents' opinions on the value of street trees depending on tree location. J. Arboric. 2004, 30, 36-44. 
17. Lorenzo, A.B.; Blanche, C.A.; Qi, Y.; Guidry, M.M. Assessing residents' willingness to pay to preserve the community urban forest: A small-city case study. J. Arboric. 2000, 26, 319-325.

18. Saz-Salazar, S.D.; Garcia-Menendez, L. Willingness to Pay for Environmental Improvements in a Large City Evidence from the Spike Model and From a Non-Parametric Approach. Environ. Resour. Econ. 2001, 20, 103-112. [CrossRef]

19. Zhang, Y.; Hussain, A.; Deng, J.; Letson, N. Public attitudes toward urban trees and supporting urban tree programs. Environ. Behav. 2007, 39, 797-814. [CrossRef]

20. Zhang, Y.; Zheng, B. Assessments of citizen willingness to support urban forestry: An empirical study in Alabama. Arboric. Urban For. 2011, 37, 119-125.

21. Zhu, P.; Zhang, Y. Demand for urban trees and economic welfare: Evidence from the Southeastern U.S. Cities. J. Agric. Appl. Econ. 2006, 38, 279-285. [CrossRef]

22. Zhu, P.; Zhang, Y. Demand for urban trees in United States cities. Landsc. Urban Plan. 2008, 84, $293-300$. [CrossRef]

23. Brody, S.D.; Highfield, W.; Alston, L. Does location matter? Measuring environmental perceptions of creeks in two San Antonio watersheds. Environ. Behav. 2004, 36, 229-250. [CrossRef]

24. Wen, Z.L.; Hau, K.T.; Herbert, W.M. Methods and recent research development in analysis of interaction effects between latent variables. Adv. Psychol. Sci. 2003, 11, 593-599.

25. State Forestry Administration P. R. China, Bulletin of China's Land Greening Situation. Available online: http:/ / www.forestry.gov.cn/main/195/content-851243.html (accessed on 1 May 2016).

26. Pan, H.L.; Tian, Y.; Dai, Y.; Wang, L.; Cai, X.H.; Wen, Z.Y. Development strategies of urban forestry under the rapid urbanization background in China. J. Sichuan For. Sci. Technol. 2011, 10, 43-46.

27. Beijing Gardening and Greening Bureau. Available online: http://www.bjyl.gov.cn/zwgk/tjxx/201705/ t20170517_192778.html (accessed on 9 January 2018).

28. Chen, W.Y.; Wang, D.T. Urban forest development in China: Natural endowment or socioeconomic product? Cities 2013, 35, 62-68. [CrossRef]

29. Junquera, B.; del Brío, J.Á.; Muñiz, M. Citizens' attitude to reuse of municipal solid waste: A practical application. Resour. Conserv. Recycl. 2001, 33, 51-60. [CrossRef]

30. Bollen, K.A. Sample size and Bentler and Bonett's nonnormed fit index. Psychometrika 1986, 51, $375-377$. [CrossRef]

31. Ji, Q.; Li, C.; Jones, P. New green theories of urban development in China. Sustain. Cities Soc. 2017, 30, $248-253$. [CrossRef]

32. Wiggins, S.; Marfo, K.; Anchirinah, V. Protecting the forest or the people? Environmental policies and livelihoods in the forest margins of Southern Ghana. World Dev. 2004, 32, 1939-1955. [CrossRef] 